NBER WORKING PAPER SERIES

\title{
DO ‘CHEESEBURGER BILLS’ WORK? EFFECTS OF TORT REFORM FOR FAST FOOD
}

\author{
Christopher S. Carpenter \\ D. Sebastian Tello-Trillo \\ Working Paper 21170 \\ http://www.nber.org/papers/w21170
NATIONAL BUREAU OF ECONOMIC RESEARCH
1050 Massachusetts Avenue
Cambridge, MA 02138

May 2015

We are grateful to Jim Blumstein, Chuck Courtemanche, Richard Daynard, Kate Fritzdixon, Jon Klick, Ben McMichael, Max Schanzenbach, Jennifer Shinall, Kip Viscusi, and seminar participants at McMaster and Vanderbilt Universities for extremely helpful comments. We are grateful to Pedro Salcido for valuable research assistance at the early stages of this project and to Steve Rogers for providing state political variables. All errors are our own. The views expressed herein are those of the authors and do not necessarily reflect the views of the National Bureau of Economic Research.

NBER working papers are circulated for discussion and comment purposes. They have not been peerreviewed or been subject to the review by the NBER Board of Directors that accompanies official NBER publications.

(C) 2015 by Christopher S. Carpenter and D. Sebastian Tello-Trillo. All rights reserved. Short sections of text, not to exceed two paragraphs, may be quoted without explicit permission provided that full credit, including $\odot$ notice, is given to the source. 
Do 'Cheeseburger Bills' Work? Effects of Tort Reform for Fast Food

Christopher S. Carpenter and D. Sebastian Tello-Trillo

NBER Working Paper No. 21170

May 2015, Revised August 2015

JEL No. I12,I18,K13

\begin{abstract}
$\underline{\text { ABSTRACT }}$
After highly publicized lawsuits against McDonald's in 2002, 26 states adopted Commonsense Consumption Acts (CCAs) - aka 'Cheeseburger Bills' - that greatly limit fast food companies' liability for weight-related harms. We provide the first evidence of the effects of CCAs using plausibly exogenous variation in the timing of CCA adoption across states. In two-way fixed effects models, we find that CCAs significantly increased stated attempts to lose weight and consumption of fruits and vegetables among heavy individuals. We also find some evidence that CCAs increased employment in fast food. Finally, we find that CCAs significantly increased the number of company-owned McDonald's restaurants and decreased the number of franchise-owned McDonald's restaurants in a state. Overall our results provide novel evidence supporting a key prediction of tort reform - that it should induce individuals to take more care - and show that industry-specific tort reforms can have meaningful effects on market outcomes.
\end{abstract}

Christopher S. Carpenter

Department of Economics

Vanderbilt University

VU Station B, Box \#351819

2301 Vanderbilt Place

Nashville, TN 37235

and NBER

christopher.s.carpenter@vanderbilt.edu

D. Sebastian Tello-Trillo

Department of Economics

Vanderbilt University

daniel.s.tello@vanderbilt.edu 


\section{Introduction}

In 2002 McDonald's corporation was the subject of two high profile lawsuits alleging liability for weight-related health claims. In the first, Caesar Barber, a severely obese 56 year old man from the Bronx, accused McDonald's and other popular fast food chains of intentionally withholding nutritional content information from customers, causing him to consume unhealthy food without his knowledge. ${ }^{1}$ In the second, the parents of Ashley Pelman and Jazlen Bradley two severely obese teenagers - sued McDonald's on the basis of deceptive marketing. Although both of these cases were ultimately dismissed, McDonald's and other fast food restaurants viewed the threat of lawsuits as non-trivial. Around this same time period, McDonald's eliminated its 'super-size' option, provided nutrition information on food packaging, and added healthier options such as salads and fruit to its menu, and other restaurants took similar actions. ${ }^{2}$

Regardless of the legal merits of claims such as those in the Barber and Pelman cases, there is strong popular belief that holding food companies legally responsible for obesity-related claims is unwarranted at best and ridiculous at worst. In response to the potentially costly effects of these and similar lawsuits, states quickly began to adopt laws that explicitly limited liability of food

\footnotetext{
${ }^{1}$ Barber also sued Burger King, Wendy's, and Kentucky Fried Chicken.

${ }^{2}$ McDonald's is no stranger to high profile lawsuits and has paid out very large jury awards and settlements in the 1994 hot coffee case, the 2005 acrylamide case, and others. More recently, in 2010 the Center for Science in the Public Interest sued McDonald's, alleging that toys in Happy Meals constituted deceptive marketing to children.
} 
companies in weight-based claims. Termed 'Commonsense Consumption Acts' (henceforth CCAs) but more commonly known as 'Cheeseburger Bills', these laws were promoted by the National Restaurant Association and achieved a great deal of success beginning as early as 2003. In June of that year, Louisiana became the first state to adopt a CCA; by the end of 2004, 12 other states had followed suit. Today, 26 states have adopted some limit on legal liability for the food industry. A federal version titled 'American Personal Responsibility in Food Consumption Act' was introduced to Congress by Florida Republican and selfacknowledged fast-food lover Ric Keller in both 2004 (HR339) and 2005 (HR554). Both times it passed in the House but did not pass the Senate.

Commonsense Consumption Acts effectively serve as tort reform for the food industry (in particular, the fast-food industry, which is the subject of most of the legal attention). These laws share several common features, and in fact many share a nearly identical structure and language (see Appendix A for an example). Specifically, the modal CCA protects food manufacturers, packers, distributors, carriers, holders, sellers, marketers, and advertisers from civil actions for claims arising out of weight gain, obesity, health conditions associated with weight gain or obesity, or other known conditions likely to result from long-term consumption of food. CCAs also generally clarify the conditions under which protection is not extended: if there is a violation of the adulteration or misbranding requirement or if there is any other knowing and willful material violation of state or federal laws 
pertaining to manufacture, sale, distribution, marketing, or labeling of food. Most laws explicitly define 'food' using the Food and Drug Administration definition that includes beverages. Some CCAs also contain explicit exceptions for altered products, deceptively advertised products, or fraudulent claims. Thus, proponents of CCAs claim that they still provide adequate protection to consumers while at the same time limiting frivolous lawsuits.

Opponents of CCAs (including the Center for Science in the Public Interest) claim that the laws are simply designed to help the large and powerful food industry - particularly fast food and the National Restaurant Association, which was the primary supporter and financial sponsor of state and federal CCA lobbying activity - make more money and avoid their responsibilities to society. Opponents also claim that the fact there have been no successful obesity-related lawsuits suggests that, in fact, the legal system in this realm is not broken - and thus there is no need to fix it. ${ }^{3}$

Indeed, the success of any such weight-based claim hinges critically on a link that many legal experts agree is the fundamental problem with such cases: establishing a causal connection between consumption at a particular restaurant

\footnotetext{
${ }^{3}$ There are examples of successful obesity-related lawsuits against McDonald's in other countries. For example, in a 2010 case in Brazil, McDonald's was ordered to pay $\$ 17,500$ to one of its managers who alleged the company contributed to his 65 pound weight gain over 12 years in part by supplying him free meals. The manager also claimed that 'mystery shoppers' sent by the firm to the store required him to eat the food to make sure it passed quality standards (Hartenstein 2010). Legal scholars have also identified other possible social benefits of nontrivial obesityrelated legal threats to fast food companies. For example, such threats may increase consumer
} 
(e.g., McDonald's) and weight-related harms. Despite this inherent legal challenge, two trends suggest that legal action against fast food companies is unlikely to go away. First, there has been a well-documented and high-profile dramatic rise in population rates of obesity. Second, there has been a concomitant reduction in the relative price of calories consumed away from home, particularly at fast food restaurants. These factors give many observers reason to believe that from a legal standpoint obesity could become the next tobacco: that is, just as the largest US tobacco companies were on the losing end of class-action lawsuits and huge jury awards for smoking-related illnesses two decades ago, experts have suggested that we might see similar obesity-related legal activity for economic and non-economic damages pertaining to weight-based health problems. ${ }^{4}$

Documenting the effects of Commonsense Consumption Acts is important for several reasons. First, our results help inform a large and growing literature in law and economics on the effects of other more traditionally studied tort reforms. Specifically, our study provides direct evidence on whether parties take more care

awareness of obesity and nutrition issues, and it also may incentivize fast food companies to voluntarily change menus or alter their marketing practices (Mello et al. 2003).

${ }^{4}$ In the debates over obesity litigation, many parallels are made with tobacco litigation. In both cases the products in question are harmful to public health if consumed in excess quantity and are potentially addictive, and in both cases there are claims that companies may have deceived consumers about the content, safety, and addictiveness of the products. Moreover, in both cases the public thought it was implausible that plaintiffs would win large jury awards. The release of tobacco industry documents through the 1998 Master Settlement Agreement - which was negotiated after several state Attorneys General filed class action lawsuits against the largest tobacco companies in the United States (RJ Reynolds and Lorillard) - helped fuel big awards. Notably, Altria Group (formerly Phillip Morris), one of the largest tobacco companies worldwide, actively lobbied for adoption of the federal cheeseburger bill. As of 2014, lawyers in at least 16 
when they are less able to sue companies for the harmful effects of products. This is a central idea behind tort reform and has been studied extensively in the context of medical malpractice. For example, multiple studies have found that tort reforms such as caps on economic damages and establishment of joint and several liability rules are associated with significant changes in the way doctors practice medicine and in health outcomes (e.g. mortality and birth outcomes) (Currie and McLeod 2008). Second, our study provides direct evidence on whether the laws are having their intended effects, as one explicit goal of CCAs was to induce people to take more personal responsibility for their food consumption and weight. Debate over these regulations remains at the top of the legislative agenda in many states: North Carolina's CCA went into effect in October 2013, while Governor Mark Dayton of Minnesota vetoed his state's CCA in May 2011. There is substantial latitude for the remaining states to adopt their own CCAs or for a federal version of a CCA to be reintroduced.

In this paper we provide the first empirical evidence on the effects of CCAs on investments in weight-related health, population weight, fast-food prices, and fast-food market size. We use several datasets and a two-way fixed effects empirical framework that identifies the effects of CCAs on outcomes using quasi-random variation in the timing of policy adoption across states, net of area (city or state) and year fixed effects, linear area-specific time trends, state 
unemployment rates and other state characteristics, and other state policies related to tort-reform (e.g., damage caps) and obesity prevention (e.g., menu labelling laws).

To preview, we find that CCAs significantly increased the likelihood that individuals state they are currently trying to lose weight. We also find that CCAs significantly increased healthy food consumption as measured by the number of servings of fruits and vegetables consumed per day. In both cases, we find that these effects are concentrated among heavy individuals. We do not find any effects of CCAs on exercise, nor do we find that the CCA-induced changes in weight loss attempts and healthy food consumption translated into contemporaneous changes in body weight. These null weight effects are precise: our large samples of individual data allow us to rule out effects of CCAs on population weight larger than 0.2 percent. We find no consistent effects of CCAs on prices of fast food or other food items. Regarding the fast-food market, we find some evidence that CCAs increased employment in fast food restaurants within the state. Finally, we show that CCAs significantly increased the number of company-owned McDonald's restaurants and reduced the number of franchiseowned McDonald's restaurants in a state. Our results are important because they provide novel evidence supporting a key tenet of tort reform - that it should 
induce parties to take more care - and demonstrate that industry-specific tort reform can affect market-wide outcomes.

The paper proceeds as follows: Section 2 outlines the mechanisms through which CCAs could plausibly have affected health and market outcomes and provides a brief literature review. Section 3 describes the data and outlines the empirical approach. Section 4 presents the results, and Section 5 discusses and concludes.

\section{Mechanisms and Literature Review}

\section{a. Mechanisms}

How might Commonsense Consumption Acts affect individual and market outcomes in fast food? There are several possible mechanisms. First, for health outcomes, there is a straightforward moral hazard explanation. This mechanism predicts that because CCAs eliminate the 'insurance' function of litigation, heavy individuals should be more likely to invest in weight-related health. That is, individuals in states without CCAs (or prior to CCA adoption) could reason that if they became sick due to their food consumption, they could plausibly have legal recourse to recover health costs and personal damages by suing food manufacturers. CCAs make this avenue substantially less attractive by providing those manufacturers some degree of immunity from weight-based claims, and as 
such the laws should be expected to induce shifts toward healthier consumption and weight loss attempts. ${ }^{5}$

A challenge with the pure moral hazard mechanism is that it requires individuals to credibly believe that they might successfully sue fast-food companies for their weight-related health costs in the absence of CCAs and to be aware of CCA adoption in their state substantially eroding this possibility. While major national newspapers and television programs covered debates over the federal Cheeseburger bill and some of the state laws, it is difficult to know who saw and read those news stories. Google Trends data confirm that there was a spike in national searches for the phrase 'Cheeseburger Bill' in late 2005 when the federal law passed the House, as well as in 2011 (when Minnesota adopted a CCA before its governor vetoed it) and in late 2013 (when North Carolina adopted a CCA) (shown in Figure 1). Unfortunately, Google Trends does not provide comparable data for individual states due to insufficiently low search volume for the specific term. ${ }^{6}$ We note that even if people did not know about CCAs in their state from local newspaper and television reports - which would be

\footnotetext{
${ }^{5}$ These effects should be concentrated among heavy individuals, as they are the most likely to suffer weight-related harms. People who are underweight may also experience increased risk for some health problems, but in those cases it is more difficult to imagine them suing food manufacturers in an attempt to recover health costs and noneconomic damages.

${ }^{6}$ Using Google Trends to provide complementary evidence for the results on weight loss intentions and healthy food consumption is complicated by two further challenges. First, Google Trends does not have any data before 2004; given that most states adopted in 2004, we cannot implement the quasi-experimental approach used in the main analyses. Second, it is not clear what the right search terms would be for each of the health outcomes for which we find significant
} 
a problem for the moral hazard story - it could be that trial lawyers seek out clients for weight-based claims, thereby disseminating relevant information. ${ }^{7}$

Another mechanism for any health effects is information. Specifically, the debates about CCA could cause individuals (particularly heavy individuals) to learn or be reminded about society's views and expectations regarding personal responsibility and weight. Even if individuals had no intentions of ever suing fast-food companies, this information channel could have changed people's behavior.

Regarding market size, CCAs should be expected to increase entry into and reduce exit from the fast food industry (thus increasing the overall fast-food market size) by lowering costs of operation, especially litigation costs and liability insurance costs, which prior work has shown is responsive to tort reform (Born et al. 2009, Viscusi and Born 2005). Prices should be plausibly affected by simple supply and demand forces: if CCAs reduce demand for fast food due to either of the channels described above for individual health outcomes and if CCAs weakly increase supply of fast food restaurants, then prices of fast food should decline. ${ }^{8}$

\section{b. Literature Review}

associations. For example, for weight loss intentions one could imagine numerous possible search terms such as 'lose weight', 'diet', 'diet foods', and others.

${ }^{7}$ Both the Barber and the Pelman cases were brought by the same lawyer (Samuel Hirsch).

${ }^{8}$ A relevant issue is the degree of latitude franchisees have at setting prices. Our price data suggest there is substantial latitude for individual restaurants to set prices, as there is a great deal of variation across locations, even within the same quarter. This basic finding is confirmed in recent work using a panel of McDonald's prices in the Bay Area (Ater and Rigbi 2007). 
Regarding prior literature related to CCAs, we are not aware of any studies in economics that evaluate their effects. Despite this gap in the literature, scholars in health policy and law have studied the public health and legal issues related to obesity litigation in general (Mello et al. 2003, Courtney 2006) and CCAs in particular (Jones 2005, Wilking and Daynard 2013). And despite the lack of specific economics evaluations of CCAs, there is a substantial literature in empirical health economics that studies the causes of the obesity epidemic (see, for example, Courtemanche et al. 2014), including studies that specifically focus on the role of restaurants (e.g., Currie et al. 2010, Chou et al. 2004).

Our work is also related to a well-developed literature in law and economics on the effects of policies such as caps on non-economic damages, caps on punitive damages, joint and several liability rules, collateral source rules, and others on outcomes such as insurance premiums (e.g. Viscusi et al 1993, Born et al 1998, Born et al. 2009, Avraham et al. 2012), defensive medicine (Kessler and McClellan 1996, Sloan and Shadle 2009), and health outcomes such as mortality and birth outcomes (Currie and McLeod 2008). More recent work has suggested that movements toward national standards of care are also important in this context (Frakes 2014).

\section{Data Description and Empirical Approach}

a. Data Description 
We use multiple datasets to test for effects of CCAs on outcomes. Our primary outcome data for adult weight-related outcomes come from public use versions of the Behavioral Risk Factor Surveillance System (BRFSS). These telephone surveys are fielded every year by state health departments and are coordinated by the Centers for Disease Control who compiles them into an annual individual level dataset that is designed to be representative at the state level. As most of the laws we study were adopted in the mid-2000s, our primary analysis sample is 2000-2012.

Individuals in the BRFSS are asked to state their height and weight (weight without shoes on). ${ }^{9}$ We use these responses to create body mass index (BMI) which equals weight in kilograms divided by height in meters squared. In addition to height and weight, individuals are also asked about several other weight-related outcomes and behaviors. We examine BRFSS outcomes related to exercise and healthy food consumption as two possibilities. Regarding exercise, the BRFSS asks respondents: "During the past month, other than your regular job, did you participate in any physical activities or exercises such as running, calisthenics, golf, gardening, or walking for exercise?" We create a variable called ANY EXERCISE that equals one if the person reported any past month exercise. Regarding healthy food consumption, the BRFSS asks respondents in several years (2000-2003, 2005, 2007, 2009, 2011, and 2012) about the number of 
servings of fruits and vegetables the individual reports eating on a usual day. ${ }^{10}$ We create a variable called TOTAL FRUITS AND VEGETABLES SERVINGS PER DAY that represents the number of total servings of fruits and vegetables the respondent reports eating per day. Finally, for a limited set of years (2000-2003, and 2005) and states we also observe responses to a question about weight intentions. Specifically, individuals are asked: "Are you now trying to lose weight?". We therefore examine an indicator variable for TRYING TO LOSE WEIGHT.

We also examine fast food prices using data from the ACCRA/C2ER database. ACCRA data were originally designed to provide cost of living estimates for urban professionals and have been collected quarterly since 1976. Typically volunteers from local Chambers of Commerce would collect information on prices of several local goods in multiple locations, and ACCRA/C2ER compiled these into a city-specific index. These data have been used extensively in the existing literature on obesity in part because of the large number of participating cities. From 2000-2012 we observe three relevant fast-

\footnotetext{
${ }^{9}$ We used adjustments for self-reported height and weight based on gender, race and age (Cawley 2004, Cawley and Burkhauser 2008, Courtemanche et al. 2014).

${ }^{10}$ Specifically, from 2000-2009 the BRFSS asks: "These next questions are about the foods you usually eat or drink. Please tell me how often you eat or drink each one. ... Include all foods you eat, both at home and away from home." Respondents can report numbers of servings consumed per day, per week, per month, or per year; we convert all responses into average number of servings consumed per day. The specific foods asked include: fruit juices such as orange, grapefruit, or tomato; fruit not counting juice; green salad; potatoes not including French fries, fried potatoes, or potato chips; carrots; and vegetables not counting carrots, potatoes, or salad. For
} 
food prices: a McDonald's Quarter Pounder with Cheese; an 11"-12" Pizza Hut or Pizza Inn thin crust cheese pizza; and a thigh and drumstick from either Kentucky Fried Chicken or Church's Chicken. We also observe prices of other food items which serve as placebo or falsification outcomes: a half gallon of whole milk, a loaf of bread, a ten pound sack of potatoes, and an overall grocery price index. ${ }^{11}$ We measure all prices in real 2010 US dollars.

We use data from the Quarterly Census of Employment and Wages (QCEW) to study effects on market size. These data are published by the Bureau of Labor Statistics (BLS) and contain quarterly counts of employment and wages reported by employers who cover 98 percent of all U.S jobs. Importantly, these data also identify the relevant industry for each employer. We use data from 2000-2012 on the number of establishments and wages for different industries, including limited-service restaurants (i.e., fast food establishments who should be most directly affected by CCAs), full-service restaurants (generally establishments with 'sit down' table service that may also be partly affected by CCAs but which were not targeted in most of the lawsuits), and other industries such as gas stations with convenience stores and grocery stores which should have been unaffected by CCAs and therefore serve as controls or placebo outcomes.

the years 2011 and 2012 the vegetables questions ask about beans, green vegetables, orange vegetables and other types of vegetables.

${ }^{11}$ We note that the sampling of the ACCRA data has some limitations, most obviously that we do not observe prices in rural markets. 
We supplement the QCEW data with information on the number of McDonald's franchises and McDonald's company owned stores in each state and year from 2000-2012. These data are reported in annual Uniform Franchising Offering Circulars (UFOC, later called Franchise Disclosure Documents after 2008). These are legal documents that the Federal Trade Commission requires each parent company to provide to potential franchisees; recent years are available on various state commerce department websites, and we supplemented these by purchasing individual years from Frandata.com. We chose McDonald's given their involvement in the major court cases that led to CCA adoption.

\section{b. Empirical Approach}

To estimate the effect of the CCAs across all the datasets, we estimate standard difference-in-differences models that rely on plausibly exogenous variation in the timing of adoption of CCAs across states. For the BRFSS-based analyses of individual level data we estimate the following model:

(1) $\mathrm{Y}_{\mathrm{ist}}=\beta_{0}+\beta_{1} \mathrm{X}_{\mathrm{ist}}+\beta_{2}(\text { COMMONSENSE CONSUMPTION ACT })_{\mathrm{st}}+\beta_{3} \mathrm{Z}_{\mathrm{st}}$

$$
+\beta_{4} \mathrm{~S}_{\mathrm{s}}+\beta_{5} \mathrm{~T}_{\mathrm{t}}+\beta_{6} \mathrm{~S}_{\mathrm{s}} * \text { TREND }+\varepsilon_{\text {ist }}
$$

where $\mathrm{Y}$ are the weight-related health outcomes available in the BRFSS data. We estimate linear probability models on the dichotomous BRFSS outcomes for ease of interpretation. $\mathrm{X}_{\mathrm{ist}}$ is a vector of individual characteristics available in the BRFSS, including: gender, age and its square, race/ethnicity (Hispanic, black, Asian, other), education (elementary, some high school, high school, some 
college, college or above), and marital status (divorced, widowed, separated, never married, member of an unmarried couple). COMMONSENSE CONSUMPTION ACT is an indicator variable equal to one in the states and periods when a CCA is in effect which we coded according to Wilking and Daynard (2013) and which is reported in Table $1 .{ }^{12}$ The coefficient of interest is $\beta_{1}$ and in the presence of state and year dummies (described below) is identified from within-state changes in outcomes coincident with variation in the timing of CCA adoption across states. The key identifying assumption is that weight and health outcomes would have evolved identically in states with and without CCAs had the laws not been adopted.

$\mathrm{Z}_{\mathrm{st}}$ is a vector of other potentially relevant state obesity-related public policies, some of which have been studied in prior work. These include: soda taxes (Fletcher, Frisvold, and Tefft 2008), complete streets laws, state and local menu labeling laws (Restrepo 2014), and cigarette taxes (Chou et al. 2004, Gruber and Frakes 2006, Courtemanche 2009). ${ }^{13}$ The $\mathrm{Z}$ vector also includes controls for more traditionally studied tort reforms (Avraham 2014), state unemployment

\footnotetext{
${ }^{12}$ The coding of the CCA variable for the BRFSS outcomes takes the value of 1 if the individual's interview date is on or after the law's effective date in the state and 0 otherwise. For the UFOC outcomes, the CCA variable takes the value of 1 for all years after the law is in effect and 0 otherwise, with the exception that for the year of adoption we set the CCA variable equal to the fraction of the year the law was in effect in the state. For the ACCRA and QCEW outcomes, the CCA variable takes the value of 1 for all the quarters after the quarter the law was effective in the state and 0 otherwise, with the exception that if a law is effective in the middle of a quarter we set the CCA variable in that quarter equal to the fraction of the quarter the law was in effect in the state.
} 
rates, and state demographic characteristics (fraction female; fraction black, Hispanic, and other non-white races; fraction of individuals with high school degrees and college or more, fraction of individuals under 21 and between 21-64; and fraction of individuals below the federal poverty line). ${ }^{14} \mathrm{~S}_{\mathrm{s}}$ and $\mathrm{T}_{\mathrm{t}}$ are a full set of state and year dummies, respectively. We also control for state-specific linear time trends where we interact each state fixed effect with a variable TREND that equals 1 in 2000, 2 in 2001, and so forth. In these BRFSS models we also control for (but do not show in equation 1) month dummies to account for seasonality in the weight-related health investments (e.g., exercise). We use sample weights provided by BRFSS, and we cluster standard errors at the state level (Bertrand, Duflo, and Mullainathan 2004). ${ }^{15}$

\footnotetext{
${ }^{13}$ Other state policies aimed at reducing obesity were also rolled out over this time period but were mainly focused on school environments and children as opposed to the adults we study here.

${ }^{14}$ State unemployment rates come from the Bureau of Labor Statistics. State demographic characteristics are from the Census Bureau.

${ }^{15}$ In results not reported but available upon request, we estimated models that predicted the number of years a CCA was in effect in a state as a function of state economic and demographic characteristics, as well as state policies related to obesity and tort reform (but excluding state fixed effects). We also controlled for the vote share to the Democratic candidate in the most recent Presidential election (to account for citizen ideology) and the share of the state legislature that is Democratic (since Democratic legislators might be friendlier to trial lawyers). Most state demographic characteristics were not significantly associated with the CCA variable except the fraction of individuals aged 65 or older in a state and the fraction of the state below the federal poverty level which were negatively and positively related to the number of years a CCA was in effect in a state, respectively. Obesity-related policies and tort reforms - either measured individually or as an index - were not meaningfully associated with the CCA variable. State unemployment rates were generally negatively related to the number of years a state had a CCA in effect. Political variables were significant predictors of CCAs, but there was a not a simple relationship: while the democratic share of the state legislature was negatively related to the number of years a CCA was in effect in a state (as expected), we also found that the vote share to the democratic candidate in the most recent Presidential election was positively related to the number of years a CCA was in effect in a state. Our main findings are robust to inclusion of these political variables.
} 
For the analysis of fast food prices we account for the city-quarter nature of the observations and estimate the following model (estimated using OLS):

(2) $\mathrm{Y}_{\mathrm{cst}}=\beta_{0}+\beta_{1}(\mathrm{COMMONSENSE} \mathrm{CONSUMPTION} \mathrm{ACT})_{\mathrm{st}}+\beta_{2} \mathrm{Z}_{\mathrm{st}}+\beta_{3} \mathrm{C}_{\mathrm{c}}$ $+\beta_{4} \mathrm{~T}_{\mathrm{t}}+\beta_{5} \mathrm{C}_{\mathrm{c}} * \mathrm{TREND}+\varepsilon_{\mathrm{cst}}$

where $\mathrm{Z}$ is as previously defined and where $\mathrm{Y}_{\mathrm{cst}}$ are the city-specific fast-food prices in city $c$ in state $s$ in quarter $t$. We replace the state dummies from equation (1) with city dummies in equation (2), and we also replace the year fixed effects with a full set of fixed effects for each unique quarter in the data. We also control for smooth linear city-specific time trends in equation (2) in place of the statespecific linear time trends in equation (1). We continue to cluster the standard errors at the state level for the prices analysis, and the key identifying assumption remains: that the evolution of local prices in states without CCAs represents what would have occurred to prices in CCA states in the absence of policy adoption.

For the QCEW data, we write the two-way fixed effects model (also estimated using OLS) as:

(3) $\mathrm{Y}_{\mathrm{st}}=\beta_{0}+\beta_{1}(\text { COMMONSENSE CONSUMPTION ACT })_{\mathrm{st}}+\beta_{2} \mathrm{Z}_{\mathrm{st}}+\beta_{3} \mathrm{~S}_{\mathrm{s}}$ $+\beta_{4} \mathrm{~T}_{\mathrm{t}}+\beta_{5} \mathrm{~S}_{\mathrm{s}} * \mathrm{TREND}+\varepsilon_{\mathrm{st}}$

where $\mathrm{Y}_{\mathrm{st}}$ are the outcomes of interest (e.g., number of establishments, number of employees, and average weekly wage). All other variables are as described above in equation (1). For analyses of the number of McDonald's restaurants using UFOC data we modify equation (3) by studying as our outcome variable the 
number of McDonald's restaurants per state (total and separately by franchiseowned and company-owned). For both the QCEW and UFOC analyses we continue to cluster standard errors at the state level, and we weight these regressions by annual state population counts. ${ }^{16}$

\section{Results}

\section{a. Weight-Related Health Investments}

We begin by presenting descriptive statistics for the weight-related health investments and individual demographics in the BRFSS data. Table 2 presents means of key variables relating to CCA prevalence, weight-related outcomes, and demographic characteristics from the BRFSS 2000-2012 sample. We report descriptive statistics for the full sample (column 1) and separately for individuals living in states that ever adopt CCAs (column 2) and individuals living in states that do not adopt CCAs (column 3). For the full sample, we find that about 41 percent of respondents report trying to lose weight. ${ }^{17}$ Fully 75 percent of the sample reports any past month exercise, while individuals report consuming 3.67 servings of fruits and vegetables per day. Average BMI in the sample is 27.61 (i.e., overweight), and nearly 30 percent of the sample is obese. Notably, 3

\footnotetext{
${ }^{16}$ Results were qualitatively similar when we estimated models in logs instead of levels or estimated outcomes on a per capita basis within each state (available upon request).

${ }^{17}$ In addition we find that 77 percent of the sample report trying to lose or maintain weight (not reported in the table). Of those trying to lose or maintain weight, 26 percent report eating less to lose weight, while 29 percent reporting exercising more.
} 
percent of the sample satisfies the definition of Class-3 obesity (i.e., BMI>40). In general we find few meaningful differences in average outcomes and characteristics for people in states with CCAs compared to those in states without CCAs.

In Table 3 we present estimates of the effects of CCAs that take explicit advantage of the plausibly exogenous variation in the timing of policy adoption across states on three measures of weight-related investments in health: the likelihood that an individual reports trying to lose weight (top panel), the number of servings of fruits and vegetables per day the individual reports consuming (middle panel), and the likelihood the person reported vigorous exercise in the past month (bottom panel). Each estimate in the table is the coefficient on the CCA variable from a separate difference in differences model with linear state trends. The first column reports estimates for the full sample, and the subsequent columns report estimates for models that restrict attention to people in each of the various (mutually exclusive) weight categories. We also report in the row just above each panel of estimates the average for each outcome variable across the various weight categories (and for the full sample for column 1). Notably, stated weight loss attempts are increasing in objective weight category, while fruit and vegetable consumption and exercise are both decreasing in objective weight category conditional on being at least normal weight. These patterns lend face validity that the data are plausibly measuring meaningful underlying constructs. 
The results in the top panel of Table 3 provide strong evidence that Commonsense Consumption Acts increased stated weight loss attempts among heavy individuals. For example, the estimate in the top panel of column 7 of Table 3 indicates that CCAs were associated with a 3.3 percentage point increase in the likelihood an individual with Class-3 obesity reports trying to lose weight. Relative to the average rate for this group, this represents about a 4.3 percent effect. For obese individuals in column 5 we find a 4 percentage point increase in weight loss intentions, or a 6.2 percent effect relative to the mean, and this estimate is statistically significant. Notably, we find that most of the estimated effects of CCAs on weight loss attempts for individuals in the lighter weight categories are smaller in magnitude and statistically insignificant.

The middle and bottom panels of Table 3 further investigate investments in weight-related health by examining healthy food consumption and exercise, respectively, from the preferred specification with state and year fixed effects and linear state trends. For fruit and vegetable consumption in the middle panel of Table 3, we find strong evidence that CCAs were associated with statistically significant increases in healthy food consumption, and these effects are particularly large in magnitude and statistically significant for the heaviest individuals. Among individuals with Class-3 obesity in column 7, we estimate that CCAs increased consumption of fruits and vegetables by a statistically significant 0.25 servings per day, or about 7.3 percent relative to the sample 
average for that group. We estimate smaller (in both absolute and relative terms) but statistically significant increases for overweight individuals in column 4 and for the full sample in column 1, while the estimates for underweight and normal weight individuals are both small and statistically insignificant. ${ }^{18}$ Turning to exercise participation in the bottom panel, we find no effects of CCAs: none of the estimates in the bottom panel of Table 3 are economically or statistically significant, indicating that CCAs did not meaningfully affect exercise activity for any group, let alone those most likely to have been treated by CCAs (i.e., heavy individuals). ${ }^{19}$

In Table 4 we report results for the effects of CCAs on weight for the full sample period 2000-2012. All estimates are from the preferred specification with state and year fixed effects and linear state trends. Notably, we find no

\footnotetext{
${ }^{18}$ Sample sizes differ across the panels of Table 3 because the weight intentions questions were only asked by a subset of states and were not asked in 2004 or after 2005. There is an emerging understanding of appropriate inference in settings with a small number of clusters; when we estimated p-values using the Wild-cluster bootstrap method (Cameron et al. 2008), the estimate in the top panel of Table 3 is no longer statistically significant at conventional levels. Note that the weight intention outcome is the only one for which we have a small number of clusters due to the BRFSS sampling structure.

${ }^{19}$ Results for the number of minutes of exercise similarly did not indicate any meaningful effects of CCAs on exercise. In results not reported but available upon request we performed many robustness exercises for the results in Table 3. Restricting the healthy food consumption analysis to the same years the weight loss attempts questions were asked (2000-2003 and 2005) did not change the main result on healthy food consumption. Those same results were also robust to excluding 2011 and 2012 to account for a change in the BRFSS sampling structure that accounts for cellphones. Results were also robust to the choice of included states; for example, dropping each CCA adopter one at a time did not change the results. Results were also similar when we excluded the linear state trends, as well as when we allowed for quadratic state trends in addition to linear trends. Adding a control for whether the state would adopt a CCA in the next year did not materially alter the significant coefficients in the top and middle panels of Table 3 , and the coefficient on future CCA adoption itself was not statistically significant.
} 
meaningful effects of CCAs on average BMI, and these null findings are precise: the estimate in column 1 can rule out reductions in BMI larger than about 0.05 , or about 0.2 percent relative to the average BMI in the population (27.9). ${ }^{20} \mathrm{We}$ similarly find very small CCA estimates on the likelihood of being at or above any of the standard weight thresholds. Even when measured against the very low rate of Class-3 obesity in the population (3.81 percent), the estimate in column 7 of Table 4 can rule out reductions in the likelihood of Class-3 obesity larger than about 2.6 percent. $^{21}$

\section{b. Fast Food Prices}

In Table 5 we turn to prices of fast-food and other food items from the ACCRA data. Table 5 shows the coefficient on the CCA indicator separately for several food-related prices in fully saturated models that include controls for city and year-quarter fixed effects and linear city-specific time trends as well as all the other policy controls and state level controls. Three prices are for fast-food items that should have been directly affected by CCAs (a McDonald's Quarter Pounder with Cheese, a Pizza Hut medium cheese pizza, and a Kentucky Fried Chicken thigh and drumstick), and we also show results for prices of three food items that

\footnotetext{
${ }^{20}$ Event study specifications - which replace the single CCA indicator variable with a series of variables representing months relative to CCA adoption in the state - confirm the null findings on population average BMI and are presented in Figure 2 for a two year period around CCA adoption. Event study figures for the probability of being at or above other weight thresholds (e.g., obese) were similar and are available upon request. Note that because height and weight were asked in every survey wave we have good coverage of data surrounding each state's CCA; most other outcomes that were not asked in every year do not support such detailed models.

${ }^{21}$ Controlling for fast food prices had no meaningful effect on any of the BRFSS-based outcomes.
} 
should not have been directly affected by CCAs (a half gallon of milk, a loaf of bread, and a ten pound sack of potatoes) as well as a summary grocery price index.

The results in Table 5 provide little evidence that CCAs affected prices at fast food restaurants. Estimates on the CCA variable for the three fast-food prices are all small in magnitude. The estimate in column 1 for a hamburger indicates that CCAs were associated with decreases in prices of about 1 percent, and the standard errors can rule out reductions in prices of larger than about 3 percent. $^{22}$ Coefficient estimates on the other food prices and the grocery price index are also small and statistically insignificant with the exception of the price of a sack of potatoes which we estimate a statistically significant reduction in price of about 6.6 percent. $^{23}$

\section{c. Fast Food Market Size}

In Table 6 we turn to the effects of CCAs on market size as measured by the QCEW data on the number of establishments, the number of employees, and average weekly wages across industries in each state and year from 2000-2012. If CCAs provide valuable protection to new entrepreneurs considering opening a

\footnotetext{
${ }^{22}$ Demand effects could differ across restaurants for a number of reasons; for example, some restaurant chains are likely more able to substitute items across a healthy/unhealthy food spectrum than others. As such, the predictions on specific fast food prices need not be the same.

${ }^{23}$ ACCRA also consistently tracked prices of other food items over our sample period, including: one pound of Blue Bonnet or Parkay margarine, one pound of bananas, one head of lettuce, one 11.5 ounce can of Maxwell House, Hills Brothers, or Folgers coffee, and one 29 ounce can of Hunt's, Del Monte, Libby's, or Lady Alberta peaches. Results on those other items are not shown
} 
restaurant or to existing firm owners in fast-food restaurants who are considering closing establishments, we might expect to see CCAs increasing the number of fast-food establishments. Moreover, we would expect weaker or no effects on establishments in other industries.

Table 6 presents estimates of the effects of CCAs on the number of establishments separately for fast-food restaurants, full service restaurants, grocery stores, and gas stations with convenience stores. Each entry in Table 6 presents the coefficient on the CCA indicator in a fully-saturated separate model with state and year fixed effects and linear state trends; the top panel reports estimates for the number of establishments, the middle panel reports estimates for the number of employees, and the bottom panel reports estimates for the average weekly wage. At the top of each panel we also report the average within each industry for the respective outcomes.

The results in Table 6 provide some evidence that CCAs increased employment in fast-food, consistent with our preferred supply-side mechanism. The point estimates on the CCA variable for number of establishments and number of employees suggest 2.2 percent and 4.5 percent increases, respectively, and the latter is statistically significant at the ten percent level. ${ }^{24}$ We find no effects on average weekly wages in fast-food, nor do we find effects on outcomes

but are available upon request. None indicated a statistically or economically significant association with CCAs. 
in other industries. The patterns in Table 6 suggest that CCAs may have increased employment in fast-food, primarily by increasing employment per store (as opposed to increasing numbers of stores).

Finally, in Table 7 we perform the parallel exercise on the number of McDonald's restaurants in each state from 2000-2012, controlling for state and year fixed effects, linear state trends, and all the state/time varying controls include in the QCEW models above. Column 1 reports the effect of CCAs on the total number of McDonald's restaurants in the state, while columns 2 and 3 separate company-owned from franchise-owned stores, respectively. The results in column 1 indicate that CCAs did not significantly change the total number of McDonald's stores in a state, but the results in columns 2 and 3 indicate that CCAs significantly increased the number of McDonald's restaurants within the state that are company owned and decreased the number of McDonald's restaurants within the state that are franchise-owned. ${ }^{25}$

\section{Discussion and Conclusion}

The results above provide the literature's first evidence on the effects of Commonsense Consumption Acts - more commonly known as 'Cheeseburger

\footnotetext{
${ }^{24}$ Although we do not observe specific restaurants in the QCEW data, it is worth noting that the supply side effects could also vary across restaurants.

${ }^{25}$ Unfortunately, we do not have data on the frequency of obesity-related lawsuits, nor do we know who is named in such lawsuits (i.e., the McDonald's corporation or the individual franchisee). We are not aware of data that would allow us to measure lawsuits against different types of named defendants, which would be useful for interpretation.
} 
Bills' - which greatly limit food companies' liability in weight-based claims. An interesting example of tort reform for a single industry, CCAs were adopted with the explicit goal of inducing people to take more personal responsibility for their weight (a central tenet of tort reform more generally). We are the first to examine how CCAs affected weight-related investments in health, finding that the laws did induce heavy people to take more care by consuming healthy food and trying to lose weight. We also show CCAs had no effects on population weight or food prices. We provide some evidence that CCAs increased employment in fast-food restaurants in a state. Finally, we show that for one specific restaurant targeted by obesity-related lawsuits (McDonald's), CCAs were associated with significant increases in the likelihood that restaurants are company-owned as opposed to franchise-owned.

There are some important limitations to the current study that should be noted. First, all of the weight, consumption, and exercise data are self-reported, though we have adjusted the reports of weight using the method outlined in Cawley and Burkhauser (2008). It is unlikely that reporting biases or errors are systematically correlated with the timing of CCA adoption, however. Second, although we observe healthy food consumption as measured by the number of servings of fruits and vegetables consumed per day, we do not observe either total food consumption or unhealthy food consumption. We interpret increases in healthy food consumption as likely evidence of substitution from unhealthy to 
healthy foods given the findings on stated weight loss intentions, though we cannot directly show that unhealthy consumption falls following adoption of CCAs. ${ }^{26}$ Third, we do not observe the activities of state public health departments to reduce adult obesity. While we have controlled flexibly for state trends and other state initiatives that have been previously studied in the literature on determinants of weight, we cannot rule out that there are other state-specific factors (e.g., outreach) that are correlated both with CCA adoption and with the weight-related outcomes we study here. ${ }^{27}$

Fourth, we do not have data on the frequency and nature of obesity-related lawsuits. This means that we do not, for example, know how frequently individual franchisees are named in such lawsuits (as opposed to the larger corporate entity), and we similarly do not know how concentrated the legal activity is toward individual companies. This information would be useful for interpreting our findings on prices, market size, and McDonald's restaurants. ${ }^{28}$

\footnotetext{
${ }^{26}$ While we cannot directly comment on unhealthy food consumption, we can disaggregate the components of fruit and vegetable consumption for the period 2000-2009 when the specific items were asked consistently. In results not reported but available upon request we find that the CCAinduced increases in fruits and vegetables consumption is concentrated among fruits, fruit juices, and green salads as opposed to potatoes and carrots. To the extent that the former are likely to be relatively healthier than the latter, this is suggestive evidence in favor of an overall improvement attributable to CCAs.

${ }^{27}$ We did not, however, find significant associations between state expenditures on health or personal health care and the presence of a state CCA.

${ }^{28}$ The UFOC documents do list pending litigation against the company to inform potential franchisees about legal risk, but annual versions of these documents over our sample period were prohibitively expensive (approximately $\$ 270$ per restaurant per year).
} 
Finally, we do not observe other firm responses to CCAs beyond the outcomes in the QCEW and UFOC for McDonald's. For example, it is plausible that McDonald's restaurants located in states with CCAs were slower to roll out 'healthier' menu options (such as salad, milk, and fruit), eliminate the 'Super Size' option, or adopt packaging with calories posted on the menu (to the extent that such decisions are not made nationally at the company level) following CCA adoption, but we do not observe these outcomes. We also do not know how seriously food companies take such weight-based claims (either in the presence or absence of CCAs), though we do know that there have been multiple high profile lawsuits filed and that the food industry has lobbied strenuously for CCAs, suggesting a nontrivial legal threat. Relatedly, we do not observe how liability insurance premiums responded to CCAs. While the protection afforded by the laws should have reduced insurance premiums for fast food companies, we cannot directly demonstrate this channel. A better understanding as to whether and to what extent fast food companies and the insurance industry responded to CCAs is an important area for future research.

Despite these limitations, our results are the first in the literature to evaluate the effects of CCAs and should provide valuable information to policymakers considering similar adoptions (as occurred as recently as 2013 in North Carolina). In doing so, our results provide novel new empirical evidence 
supporting a central tenet of tort reform that parties take more care and also show that industry-specific tort reforms can affect market-wide outcomes. 


\section{BIBLIOGRAPHY}

Ater, Itai and Oren Rigbi (2007). "Price Control in Franchised Chains: The Case of McDonald's Dollar Menu," Stanford Institute for Economic Policy Research Discussion Paper No. 06-22.

Avraham, Ronen (2014). "Database of State Tort Law Reforms, $5^{\text {th }}$ Edition". Accessed at: http://www.utexas.edu/law/faculty/ravraham/dstlr.html on September 30, 2014.

Avraham, Ronen, Leemore Dafny, and Max Schanzenbach (2012). "The Impact of Tort Reform on Employer-Sponsored Health Insurance Premiums," Journal of Law, Economics, and Organization, 28(4): 657-686.

Born, Patricia, W. Kip Viscusi, and Tom Baker (2009). "The Effects of Tort Reform on Medical Malpractice Insurers' Ultimate Losses," Journal of Risk and Insurance, 76(1): 197-219.

Bertrand, Marianne, Esther Duflo, and Sendhil Mullainathan (2004). "How Much Should We Trust Difference-In-Differences Estimates?," Quarterly Journal of Economics, 119(1): 249-275.

Born, Patricia H., and W. Kip Viscusi (1998). "The Distribution of the Insurance Market Effects of Tort Liability Reforms," Brookings Papers on Economic Activity: Microeconomics, pp. 55-100.

Cameron, A. Colin, Jonah Gelbach, and Douglas Miller (2008). "BootstrapBased Improvements for Inference with Clustered Errors," Review of Economics and Statistics, 90(3): 414-427.

Cawley, John (2004). "The Impact of Obesity on Wages," Journal of Human Resources, 39(2): 451-474.

Cawley, John and Richard Burkhauser (2008). "Beyond BMI: The Value of More Accurate Measures of Fatness and Obesity in Social Science Research," Journal of Health Economics, 27(2): 519-529.

Chou, Shin-Yi, Michael Grossman, and Henry Saffer (2004). "An Economic Analysis of Adult Obesity: Results from the Behavioral Risk Factor Surveillance System,” Journal of Health Economics, 23: 565-587. 
Courtemanche, Charles (2009). "Rising Cigarette Prices and Rising Obesity: Coincidence or Unintended Consequence?" Journal of Health Economics, 28(4): 781-798.

Courtemanche, Charles, Josh Pinkston, Christopher Ruhm, and George Wehby (2014). "Can Changing Economic Factors Explain the Rise in Obesity?" working paper.

Courtemanche, Charles, Josh Pinkston, and Jay Stewart (2014). "Adjusting Body Mass for Measurement Error with Invalid Validation Data," National Bureau of Economic Research Working Paper No. 19928.

Courtney, Brooke (2006). "Is Obesity Really the Next Tobacco? Lessons Learned from Tobacco for Obesity Litigation," Annals of Health Law, 15(1): 61-106.

Currie, Janet, Stefano DellaVigna, Enrico Moretti, and Vikram Pathania (2010). "The Effect of Fast Food Restaurants on Obesity and Weight Gain," American Economic Journal - Economic Policy, 2: 32-63.

Currie, Janet and Bentley McLeod (2008). "First Do No Harm? Tort Reform and Birth Outcomes," Quarterly Journal of Economics, 123(2): 795-830.

Evich, Helena B. (2014). "The plot to make Big Food pay," Politico article, February 12, $2014 . \quad$ Available here: http://www.politico.com/story/2014/02/food-industry-obesity-health-carecosts-103390.html (accessed March 4, 2015).

Fletcher, Jason, David Frisvold, and Nathan Tefft (2010). "The effects of soft drink taxes on child and adolescent consumption and weight outcomes," Journal of Public Economics, 94(11): 967-974.

Frakes, Michael (2013). "The Impact of Medical Liability Standards on Regional Variations in Physician Behavior: Evidence from the Adoption of National-Standard Rules," American Economic Review, 103(1): 257-76.

Gruber, Jonathan and Michael Frakes (2006). "Does falling smoking lead to rising obesity?," Journal of Health Economics, 25: 183-197.

Hartenstein, Meena (2010). "McDonald's ordered to pay ex-employee $\$ 17,500$ for 65 pounds he gained on the job in Brazil," New York Daily News 
article, October 28, 2010. Available here: http://www.nydailynews.com/news/world/mcdonald-ordered-pay-exemployee-17-500-65-pounds-gained-job-brazil-article-1.192584 (accessed December 4, 2014).

Jones, Norah Leary (2005). “The Illinois Commonsense Consumption Act: End of the Road for Fast Food Litigation in Illinois?" Loyola University Chicago Law Journal, 36(3): 983-1044.

Kessler, Daniel and Mark McClellan (1996). "Do Doctors Practice Defensive Medicine," The Quarterly Journal of Economics, 111(2): 353-390.

Mello, Michelle M., Eric B. Rimm, and David M. Studdert (2003). "The McLawsuit: The Fast-Food Industry and Legal Accountability for Obesity," Health Affairs, 22(6): 207-216.

Orlando Sentinel (2005). "Keller has heart surgery," October 20, 2005. Accessed September 14, 2014 at: http://articles.orlandosentinel.com/2005-1020/news/MCFBRIEFS20_5_1_ric-keller-heart-arrhythmia-cheeseburger.

Restrepo, Brandon (2014). "Calorie Labeling in Chain Restaurants and Body Weight: Evidence from New York," Max Weber Programme Working Paper 2014/05.

Silver, Diana, and James Macinko. State Health Policy Research Dataset (SHEPRD): 1980-2010. ICPSR34789-v3. Ann Arbor, MI: Interuniversity Consortium for Political and Social Research [distributor], 2014-09-24.

Sloan, Frank A. and Justin G. Trogdon (2004). "The Impact of the Master Settlement Agreement on Cigarette Consumption," Journal of Policy Analysis and Management, 23(4): 843-855.

Sloan Frank A. and John H. Shadle (2009) "Is there empirical evidence for defensive medicine? A reassessment" Journal of Health Economics, 28(2):481-91

Wilking, Cara L. and Richard A. Daynard (2013). "Beyond Cheeseburgers: The Impact of Commonsense Consumption Acts on Future Obesity-Related Lawsuits," Food and Drug Law Journal, 68(3): 229-239. 
Viscusi, W. Kip and Patricia Born (2005). "Damages Caps, Insurability, and the Performance of Medical Malpractice Insurance," The Journal of Risk and Insurance, 72(1): 23-43.

Viscusi, W. Kip, Richard J. Zeckhauser, Patricia Born, and Glenn Blackmon (1993). "The Effect of 1980s Tort Reform Legislation on General Liability and Medical Malpractice Insurance," Journal of Risk and Uncertainty, vol. 6 (1993), pp. 165-186. 


\section{Figure 1}

Searches for 'Cheeseburger Bill' - Google Trends

Compare Locatans -
$\mid \begin{aligned} & \text { cheeseburger bill } \\ & \text { Sewtin iem }\end{aligned}$
United States + Adid location

Interest over time

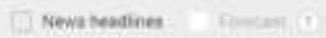
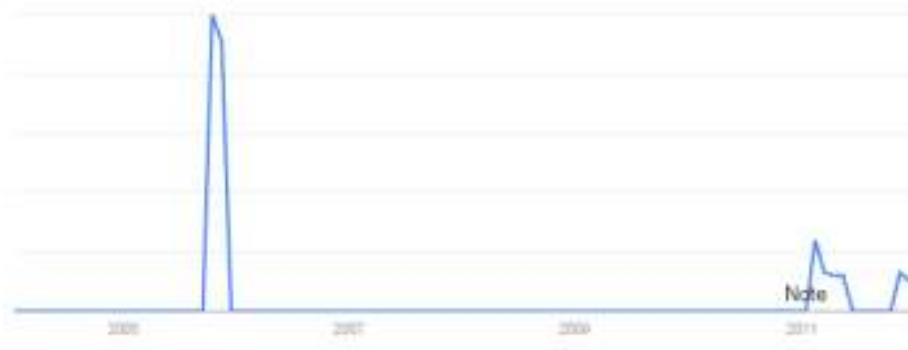
Figure 2

Event Study Estimates of CCAs on Population Average BMI

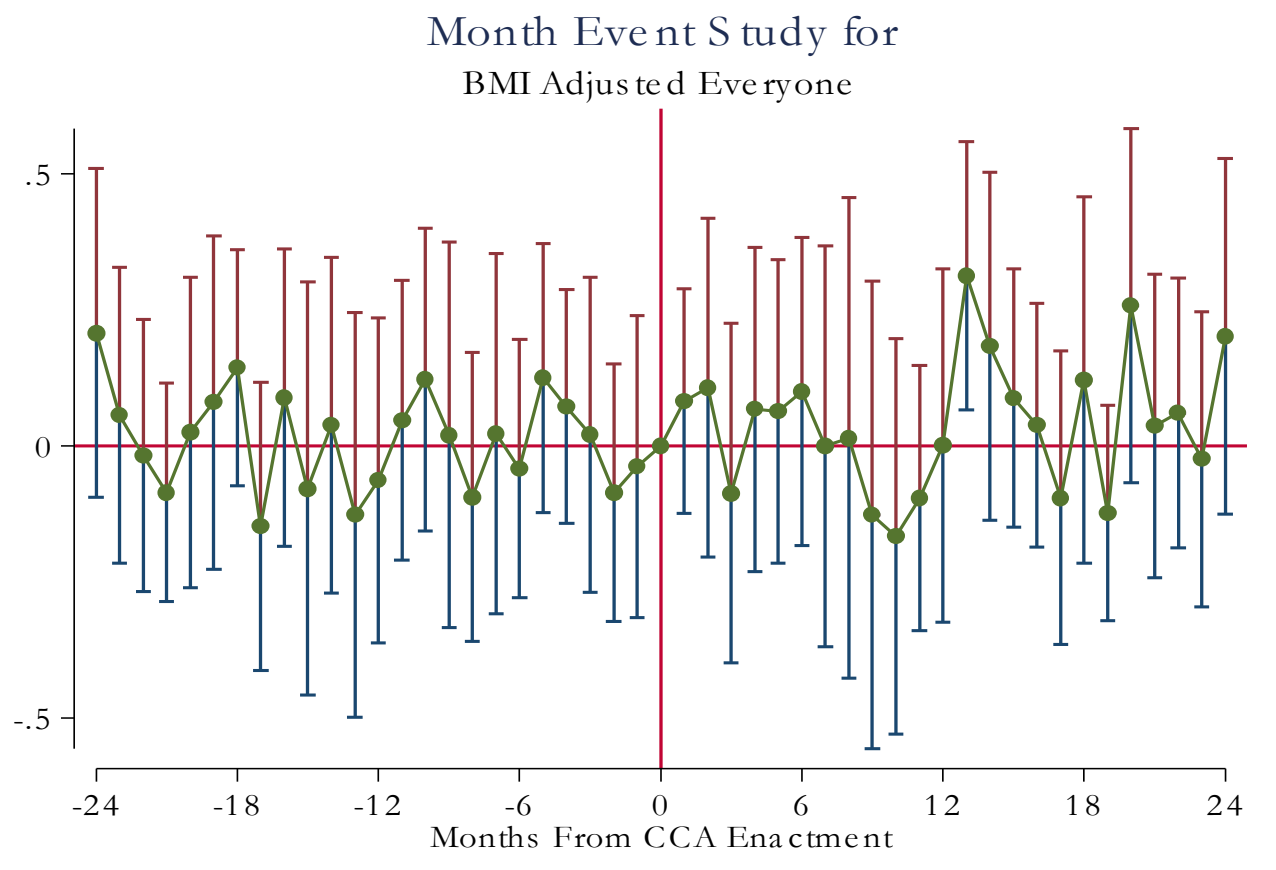


Table 1:

Timing of CCA Adoption

\begin{tabular}{|c|c|c|c|}
\hline & Enacted & Effective & Citation \\
\hline $\mathrm{AL}$ & -- & $5 / 23 / 2012$ & ALA. CODE $\S \S 6-5-730$ to 6-5-736 (2012) \\
\hline AZ & $4 / 8 / 2004$ & -- & ARIZ. REV. STAT. ANN. §§ 12-683, 12-688 (2012) \\
\hline $\mathrm{CO}$ & $5 / 17 / 2004$ & $5 / 17 / 2004$ & $\begin{array}{l}\text { COLO. REV. STAT. } \S \S \begin{array}{l}13-21-1101 \\
\text { 2012) }\end{array} \\
\text { 13-21-1106 (West }\end{array}$ \\
\hline FL & $5 / 21 / 2004$ & $5 / 21 / 2004$ & FLA. STAT. ANN § 768.37 (West 2012) \\
\hline GA & $5 / 14 / 2004$ & $5 / 14 / 2004$ & GA. CODE ANN. $\S \S 26-2-430$ to $26-2-436$ (West 2102) \\
\hline ID & $4 / 2 / 2004$ & $7 / 1 / 2004$ & IDAHO CODE ANN. $\S \S 39-8701$ to 39-8706 (2012) \\
\hline IL & $7 / 30 / 2004$ & $1 / 1 / 2005$ & ILL. COMP. STT. ANN 43/1 to 43/20 (West 2012) \\
\hline IN & $3 / 17 / 2006$ & $7 / 1 / 2006$ & IND. CODE ANN. $\S \S 34-30-23-1$ to $34-30-23-3$ (West 2012) \\
\hline KS & $4 / 15 / 2005$ & -- & KAN. STAT. ANN. § 60-4801 (2012) \\
\hline KY & $3 / 8 / 2005$ & -- & KY. REV. STAT. ANN §§ 411.600 to 411.640 (West 2012) \\
\hline LA & $6 / 2 / 2003$ & $6 / 3 / 2003$ & LA. REV. STAT. ANN § 9:2799.6 (2012) \\
\hline ME & $6 / 9 / 2005$ & -- & ME. REV. STAT. ANN. tit. 14, § 170 (2012) \\
\hline MI & $10 / 7 / 2004$ & $10 / 7 / 2004$ & MICH. COMP. LAWS ANN. § 600.2974 (West 2012) \\
\hline MO & $6 / 25 / 2004$ & $1 / 1 / 2005$ & MO. ANN. STAT. § 537.595 (West 2012) \\
\hline ND & $3 / 3 / 1 / 2005$ & $3 / 31 / 2005$ & N.D. CENT. CODE §§ 19-23-01 to 19-23-03 (2012) \\
\hline $\mathrm{OH}$ & -- & $4 / 7 / 2005$ & OHIO REV. CODE ANN. § 2305.36 (West 2012) \\
\hline OK & $5 / 22 / 2009$ & $11 / 1 / 2009$ & OKLA. STAT. ANN. tit. 76, §§ 34 to 37 (West 2012) \\
\hline OR & $7 / 27 / 2005$ & -- & OR. REV. STAT. ANN. § 30.961 (West 2012) \\
\hline SD & $3 / 9 / 2004$ & -- & S.D. CODIFIED LAWS $\S \S 21-61-1$ to 21-61-4 (2012) \\
\hline $\mathrm{TN}$ & $4 / 30 / 2004$ & $7 / 1 / 2004$ & TENN. CODE ANN. § 29-34-205 (West 2012) \\
\hline TX & $6 / 18 / 2005$ & $6 / 18 / 2005$ & $\begin{array}{l}\text { TEX. CIV. PRAC. \& REM. CODE ANN. } \S 138.001 \text { to } \\
138.004 \text { (Vernon 2012) }\end{array}$ \\
\hline UT & $3 / 19 / 2004$ & $5 / 3 / 2004$ & UTAH CODE ANN $\S \S 78 b-4-301$ to 78B-4-306 (West 2012) \\
\hline WA & $3 / 26 / 2004$ & $6 / 10 / 2004$ & WASH. REV. CODE ANN. § 7.72.070 (West 2012) \\
\hline WI & -- & $3 / 28 / 2008$ & WIS. STAT. ANN. § 895.506 (West 2012) \\
\hline WY & $2 / 24 / 2005$ & -- & WYO. STAT. ANN. §§ 11-47-101 to 11-47-103 (2012) \\
\hline
\end{tabular}

Source: Wilking \& Daynard (2013). This list excludes Minnesota which passed a CCA that was subsequently vetoed by its Governor in 2011. It also excludes North Carolina which adopted a CCA that did not take effect until October 2013, after the end of our sample period. 
Table 2:

Descriptive Statistics, 2000-2012 BRFSS Data

\begin{tabular}{|c|c|c|c|}
\hline Variable & $\begin{array}{c}\text { (1) } \\
\text { Full sample }\end{array}$ & $\begin{array}{c}\text { (2) } \\
\text { Individuals in } \\
\text { states that ever } \\
\text { adopt a CCA }\end{array}$ & $\begin{array}{c}(3) \\
\text { Individuals in } \\
\text { states that } \\
\text { never adopt a } \\
\text { CCA }\end{array}$ \\
\hline \multicolumn{4}{|l|}{ Weight Intentions } \\
\hline Trying to lose weight & 0.41 & 0.40 & 0.42 \\
\hline $\begin{array}{l}\text { \# servings of fruits and vegetables per } \\
\text { day }\end{array}$ & 3.67 & 3.59 & 3.76 \\
\hline Any exercise last month & 0.75 & 0.75 & 0.75 \\
\hline \multicolumn{4}{|l|}{ Weight Outcomes } \\
\hline BMI & 27.61 & 27.70 & 27.52 \\
\hline Underweight (BMI: less than 18.5) & 0.02 & 0.02 & 0.02 \\
\hline Normal weight (BMI:18.5 - 24.9) & 0.34 & 0.33 & 0.34 \\
\hline Overweight (BMI: 25.0 to 29.9) & 0.36 & 0.36 & 0.37 \\
\hline Obese (BMI: $30.0 \&$ above) & 0.18 & 0.18 & 0.18 \\
\hline $\mathrm{BMI}>35$ & 0.07 & 0.07 & 0.07 \\
\hline Class- 3 obesity $(\mathrm{BMI}>40)$ & 0.03 & 0.03 & 0.03 \\
\hline \multicolumn{4}{|l|}{ Demographics } \\
\hline Female & 0.51 & 0.51 & 0.51 \\
\hline Age & 45.99 & 46.06 & 45.92 \\
\hline Less than high school degree & 0.12 & 0.12 & 0.13 \\
\hline High school degree & 0.30 & 0.31 & 0.28 \\
\hline Some college & 0.27 & 0.28 & 0.26 \\
\hline \multicolumn{4}{|l|}{ BA or more } \\
\hline Married & 0.58 & 0.59 & 0.56 \\
\hline Black & 0.10 & 0.10 & 0.10 \\
\hline Asian & 0.03 & 0.02 & 0.04 \\
\hline Other race & 0.04 & 0.03 & 0.04 \\
\hline Hispanic & 0.14 & 0.11 & 0.18 \\
\hline
\end{tabular}

Weighted means. 
Table 3:

CCAs Induced Modest Improvements in Weight-Related Health Investments among Heavy Individuals BRFSS 2000-2012

\begin{tabular}{|c|c|c|c|c|c|c|c|}
\hline & & & & & & & \\
\hline Sample is $\rightarrow$ & $\begin{array}{c}\text { (1) } \\
\text { Full sample }\end{array}$ & $\begin{array}{c}(2) \\
\text { Under } \\
\text { weight } \\
\text { BMI }<18.5\end{array}$ & $\begin{array}{c}(3) \\
\text { Normal } \\
\text { Weight } \\
18.5 \leq \mathrm{BMI}< \\
25 \\
\end{array}$ & $\begin{array}{c}\text { (4) } \\
\text { Overweight } \\
25 \leq \mathrm{BMI}<30\end{array}$ & $\begin{array}{c}(5) \\
\text { Obese } \\
30 \leq \mathrm{BMI}<35\end{array}$ & $\begin{array}{c}(6) \\
\text { Severe } \\
\text { Obese } \\
35 \leq \mathrm{BMI}<40\end{array}$ & $\begin{array}{c}(7) \\
\text { Class III } \\
\text { Obese } \\
40 \leq \text { BMI }\end{array}$ \\
\hline Trying to lose weight (avg $\rightarrow$ ) & .42 & .03 & .20 & .46 & .65 & .72 & .77 \\
\hline CCA & $\begin{array}{c}0.009 \\
(0.019)\end{array}$ & $\begin{array}{c}0.008 \\
(0.023)\end{array}$ & $\begin{array}{c}-0.018 \\
(0.013)\end{array}$ & $\begin{array}{c}-0.001 \\
(0.013)\end{array}$ & $\begin{array}{c}0.040 * * \\
(0.013)\end{array}$ & $\begin{array}{l}-0.001 \\
(0.014)\end{array}$ & $\begin{array}{c}0.033 \\
(0.025)\end{array}$ \\
\hline $\begin{array}{l}\mathrm{R} \text { squared } \\
\mathrm{N}\end{array}$ & $\begin{array}{c}.05 \\
590653\end{array}$ & $\begin{array}{c}.06 \\
9669\end{array}$ & $\begin{array}{c}.08 \\
191266\end{array}$ & $\begin{array}{c}.09 \\
188779\end{array}$ & $\begin{array}{c}.05 \\
87925\end{array}$ & $\begin{array}{c}.04 \\
31517\end{array}$ & $\begin{array}{c}.04 \\
15076\end{array}$ \\
\hline \# fruit/veggie per day (avg $\rightarrow$ ) & 3.676 & 3.678 & 3.862 & 3.668 & 3.533 & 3.441 & 3.380 \\
\hline CCA & $\begin{array}{c}0.058 * * \\
(0.028)\end{array}$ & $\begin{array}{c}0.113 \\
(0.113)\end{array}$ & $\begin{array}{c}0.061 \\
(0.042)\end{array}$ & $\begin{array}{c}0.130 * * * \\
(0.033)\end{array}$ & $\begin{array}{c}0.063 \\
(0.0654)\end{array}$ & $\begin{array}{c}0.0014 \\
(0.051)\end{array}$ & $\begin{array}{c}0.246 * * \\
(0.105)\end{array}$ \\
\hline $\begin{array}{l}\mathrm{R} \text { squared } \\
\mathrm{N}\end{array}$ & $\begin{array}{c}.05 \\
2339201\end{array}$ & $\begin{array}{c}.07 \\
33913\end{array}$ & $\begin{array}{c}.05 \\
679503\end{array}$ & $\begin{array}{c}.05 \\
752056\end{array}$ & $\begin{array}{c}.05 \\
387990\end{array}$ & $\begin{array}{c}.04 \\
149813\end{array}$ & $\begin{array}{c}.05 \\
76680\end{array}$ \\
\hline Exercised past month (avg $\rightarrow$ ) & .74 & .66 & .80 & .77 & .70 & .63 & .54 \\
\hline CCA & $\begin{array}{l}-0.005 \\
(0.004)\end{array}$ & $\begin{array}{l}-0.003 \\
(0.023)\end{array}$ & $\begin{array}{c}-0.008 \\
(0.006)\end{array}$ & $\begin{array}{c}-0.004 \\
(0.007)\end{array}$ & $\begin{array}{l}-0.001 \\
(0.006)\end{array}$ & $\begin{array}{c}0.010 \\
(0.009)\end{array}$ & $\begin{array}{l}-0.012 \\
(0.13)\end{array}$ \\
\hline $\begin{array}{l}\mathrm{R} \text { squared } \\
\mathrm{N}\end{array}$ & $\begin{array}{c}.08 \\
4404754\end{array}$ & $\begin{array}{c}.09 \\
63149\end{array}$ & $\begin{array}{c}.08 \\
1260866\end{array}$ & $\begin{array}{c}.08 \\
1414696\end{array}$ & $\begin{array}{c}.07 \\
737495\end{array}$ & $\begin{array}{c}.08 \\
285528\end{array}$ & $\begin{array}{c}.08 \\
146694\end{array}$ \\
\hline
\end{tabular}

* significant at 10\%; ** significant at 5\%; *** significant at 1\%. Results are from linear probability models and use BRFSS sampling weights. All models include controls for individual demographic characteristics (age, gender, race, education level, marital status); state, month, and year fixed effects; linear state-specific time trends; soda and cigarette taxes; menu labelling laws; complete streets laws; other tort-reforms; state unemployment rates; and state demographic characteristics (fraction female, fraction black, Hispanic, and other races, fraction of individuals of age 21 to 64 and 64 to 65, fraction of individuals with high school degree and with some college or more, and fraction below the federal poverty level). Standard errors clustered at the state level. All include weights provided by BRFSS. 
Table 4:

CCAs Had No Effects on Population Weight

\begin{tabular}{|c|c|c|c|c|c|c|c|}
\hline Outcome is $\rightarrow$ & $\begin{array}{c}(1) \\
\text { BMI }\end{array}$ & $\begin{array}{c}(2) \\
\operatorname{Pr}(B M I \geq 18.5)\end{array}$ & $\begin{array}{c}(3) \\
\operatorname{Pr}(B M I \geq 20\end{array}$ & $\begin{array}{c}(4) \\
\operatorname{Pr}(B M I \geq 25)\end{array}$ & $\begin{array}{c}(5) \\
\operatorname{Pr}(\mathrm{BMI} \geq 30)\end{array}$ & $\begin{array}{c}(6) \\
\operatorname{Pr}(\mathrm{BMI} \geq 35)\end{array}$ & $\begin{array}{c}(7) \\
\operatorname{Pr}(\mathrm{BMI} \geq 40)\end{array}$ \\
\hline Sample average $\rightarrow$ & 27.88 & .984 & .954 & .661 & .299 & .110 & .038 \\
\hline $\mathrm{CCA}$ & $\begin{array}{c}0.029 \\
(0.042)\end{array}$ & $\begin{array}{c}-0.001 \\
(0.001)\end{array}$ & $\begin{array}{c}0.000 \\
(0.001)\end{array}$ & $\begin{array}{c}0.000 \\
(0.003)\end{array}$ & $\begin{array}{c}0.004 \\
(0.004)\end{array}$ & $\begin{array}{c}0.003 \\
(0.002)\end{array}$ & $\begin{array}{c}0.001 \\
(0.001)\end{array}$ \\
\hline $\begin{array}{l}\mathrm{R} \text { squared } \\
\mathrm{N}\end{array}$ & $\begin{array}{c}.062 \\
3,931,002\end{array}$ & $\begin{array}{c}.009 \\
3,931,002\end{array}$ & $\begin{array}{c}.025 \\
3,931,002\end{array}$ & $\begin{array}{c}.065 \\
3,931,002\end{array}$ & $\begin{array}{c}.038 \\
3,931,002\end{array}$ & $\begin{array}{c}.026 \\
3,931,002\end{array}$ & $\begin{array}{c}.018 \\
3,931,002\end{array}$ \\
\hline
\end{tabular}

* significant at $10 \%$;** significant at $5 \%$; *** significant at $1 \%$. See notes to Table 3 . 
Table 5:

CCAs Had No Systematic Effects on Fast Food or Other Food Prices ACCRA/C2ER 2000-2012

\begin{tabular}{|c|c|c|c|c|c|c|c|}
\hline \multicolumn{8}{|c|}{-} \\
\hline & (1) & (2) & (3) & (4) & (5) & (6) & (7) \\
\hline Outcome is $\rightarrow$ & $\begin{array}{l}\text { McDonald's } \\
\text { quarter } \\
\text { pounder with } \\
\text { cheese }\end{array}$ & $\begin{array}{c}\text { Pizza Hut } \\
\text { medium } \\
\text { cheese pizza }\end{array}$ & $\begin{array}{l}\text { Kentucky } \\
\text { Fried Chicken } \\
\text { thigh and } \\
\text { drumstick }\end{array}$ & $\begin{array}{l}\text { Half gallon of } \\
\text { milk }\end{array}$ & Loaf of bread & $\begin{array}{c}\text { Ten pound } \\
\text { sack of } \\
\text { potatoes }\end{array}$ & $\begin{array}{l}\text { Grocery price } \\
\text { index }\end{array}$ \\
\hline Average price $\rightarrow$ & 2.52 & 11.01 & 1.18 & 2.16 & 1.28 & 3.81 & 99.95 \\
\hline $\mathrm{CCA}$ & $\begin{array}{l}-0.028 \\
(0.027)\end{array}$ & $\begin{array}{l}-0.007 \\
(0.086)\end{array}$ & $\begin{array}{c}0.024 \\
(0.017)\end{array}$ & $\begin{array}{c}0.039 \\
(0.031)\end{array}$ & $\begin{array}{l}-0.024 \\
(0.018)\end{array}$ & $\begin{array}{c}-0.252 * * * \\
(0.060)\end{array}$ & $\begin{array}{l}-0.767 \\
(0.839)\end{array}$ \\
\hline R-squared & .69 & 0.76 & 0.67 & 0.77 & 0.75 & 0.76 & 0.88 \\
\hline $\mathrm{N}$ & 14938 & 14938 & 14938 & 14938 & 14938 & 14398 & 14398 \\
\hline
\end{tabular}

* significant at 10\%; ** significant at 5\%; *** significant at 1\%. Each entry is from a separate model and shows the coefficient on the CCA variable on the local price for the item at the top of each column. All models include controls for city and quarter fixed effects; linear cityspecific time trends; soda and cigarette taxes; menu labelling laws; complete street laws; other tort-reforms; and state unemployment rates; and state demographic characteristics (fraction female, fraction black, Hispanic, and other races, fraction of individuals of age 21 to 64 and 64 to 65 , fraction of individuals with high school degree and with some college or more, and fraction below the federal poverty level). Standard errors are clustered throughout at the state level. All include state population weights. 
Table 6:

Some Evidence that CCAs Increased Employment in Fast Food

QCEW 2000-2012

\begin{tabular}{|c|c|c|c|c|}
\hline Industry is $\rightarrow$ & $\begin{array}{c}\text { (1) } \\
\text { Limited-service } \\
\text { restaurants (fast-food) }\end{array}$ & $\begin{array}{l}\text { (2) } \\
\text { Full-service } \\
\text { restaurants } \\
\end{array}$ & $\begin{array}{c}\text { (3) } \\
\text { Grocery stores }\end{array}$ & $\begin{array}{c}\text { (4) } \\
\text { Gas station with } \\
\text { convenience store }\end{array}$ \\
\hline Number of establishments (avg $\rightarrow$ ) & 3781.9 & 3983.6 & 689.7 & 1786.9 \\
\hline $\begin{array}{l}\mathrm{CCA} \\
\mathrm{R} \text { squared } \\
\mathrm{N}\end{array}$ & $\begin{array}{c}82.97 \\
(79.18) \\
.99 \\
662\end{array}$ & $\begin{array}{c}-20.19 \\
(85.73) \\
.99 \\
662\end{array}$ & $\begin{array}{c}11.01 \\
(24.68) \\
.99 \\
660\end{array}$ & $\begin{array}{c}-.33 .01 \\
(46.43) \\
.99 \\
660\end{array}$ \\
\hline Number of Employees (avg $\rightarrow$ ) & 65316.5 & 84469.62 & 13763.27 & 146682.5 \\
\hline $\mathrm{CCA}$ & $\begin{array}{l}2908.49 * \\
(1584.87)\end{array}$ & $\begin{array}{c}1655.95 \\
(1644.22)\end{array}$ & $\begin{array}{c}321.87 \\
(372.15)\end{array}$ & $\begin{array}{l}-523.33 \\
(409.95)\end{array}$ \\
\hline $\mathrm{R}$ squared & .99 & .99 & .99 & .99 \\
\hline $\mathrm{N}$ & 662 & 662 & 660 & 660 \\
\hline Average weekly wage (avg $\rightarrow$ ) & 246.83 & 300.31 & 894.26 & 350.78 \\
\hline $\mathrm{CCA}$ & $\begin{array}{l}-2.29 \\
(1.89)\end{array}$ & $\begin{array}{l}-0.18 \\
(2.00)\end{array}$ & $\begin{array}{l}10.84 \\
(7.37)\end{array}$ & $\begin{array}{l}-1.46 \\
(4.33)\end{array}$ \\
\hline R squared & .98 & .99 & .97 & .93 \\
\hline $\mathrm{N}$ & 662 & 662 & 660 & 660 \\
\hline
\end{tabular}

* significant at 10\%; ** significant at 5\%; *** significant at 1\%. Each entry is from a separate model and shows the coefficient on the CCA variable on the outcome at the top of each panel (number of establishments, number of employees, and average weekly wage) for the industries in each column (limited service restaurants, full service restaurants, grocery stores, and gas stations with convenience stores). All models include controls for state and year fixed effects; linear state-specific time trends; soda and cigarette taxes; menu labelling laws; complete street laws; other tort-reforms; and state unemployment rates; and state demographic characteristics (fraction female, fraction black, Hispanic, and other races, fraction of individuals of age 21 to 64 and 64 to 65, fraction of individuals with high school degree and with some college or more, and fraction below the federal poverty level). Standard errors are clustered throughout at the state level. All include state population weights. 
Table 7:

CCAs Increased Company-Owned and Reduced Franchise-Owned McDonald's UFOC/FDD 2000-2012

\begin{tabular}{|c|c|c|c|}
\hline \multicolumn{4}{|c|}{ UTOCIFDD $2000-2012$} \\
\hline & (1) & (2) & (3) \\
\hline Outcome is $\rightarrow$ & Total \# McDonald's in the state & $\begin{array}{l}\text { \# Company-Owned McDonald's } \\
\text { in the state }\end{array}$ & $\begin{array}{l}\text { \# Franchise-Owned McDonald's } \\
\text { in the state }\end{array}$ \\
\hline$(\operatorname{avg} \rightarrow)$ & 269.07 & 36.43 & 232.65 \\
\hline $\mathrm{CCA}$ & $\begin{array}{c}2.27 \\
(2.64)\end{array}$ & $\begin{array}{c}11.16^{* * * *} \\
(3.62)\end{array}$ & $\begin{array}{c}-8.891 * * \\
(3.86)\end{array}$ \\
\hline $\mathrm{R}$ squared & 0.99 & 0.98 & 0.99 \\
\hline $\mathrm{N}$ & 662 & 662 & 662 \\
\hline
\end{tabular}




\section{APPENDIX A Sample Commonsense Consumption Act (Missouri)}

\section{TITLE 36. STATUTORY ACTIONS AND TORTS (Chs. 521-538) CHAPTER 537. TORTS AND ACTIONS FOR DAMAGES COMMONSENSE CONSUMPTION FUND}

$$
\S 537.595 \text { R.S.Mo. (2014) }
$$

$\S 537.595$. Citation -- definitions -- immunity from liability for claims relating to weight gain or obesity, when, exceptions -- petition, contents -- effective date

1. This section may be known as the "Commonsense Consumption Act".

2. As used in this section, the following terms mean:

(1) "Claim", any claim by or on behalf of a natural person, as well as any derivative or other claim arising therefrom asserted by or on behalf of any other person;

(2) "Generally known condition allegedly caused by or allegedly likely to result from long-term consumption", a condition generally known to result or to likely result from the cumulative effect of consumption and not from a single instance of consumption;

(3) "Knowing or willful violation of federal or state law", that:

(a) The conduct constituting the violation was committed with the intent to deceive or injure consumers or with actual knowledge that such conduct was injurious to consumers; and

(b) The conduct constituting the violation was not required by regulations, orders, rules, or other pronouncements of, or statutes administered by, a federal, state, or local government agency;

(4) "Other person", any individual, corporation, company, association, firm, partnership, society, joint-stock company, or any other entity, including any governmental entity or private attorney general.

3. Except as exempted in subsection 4 of this section, a manufacturer, packer, distributor, carrier, holder, seller, marketer, retailer, or advertiser of a food, as defined in the Federal Food, Drug, and Cosmetic Act (21 U.S.C. 321(f)), as amended, but shall not include alcoholic beverages, or an association of one or more such entities shall not be subject to civil liability under any state law, including all statutes, regulations, rules, common law, public policies, court or administrative decisions or decrees, or other state actions having the effect of law, 
for any claim arising out of weight gain, obesity, or a health condition associated with weight gain or obesity.

4. The provisions of subsection 3 of this section shall not preclude civil liability where the claim of weight gain, obesity, health condition associated with weight gain or obesity, or other generally known condition allegedly caused by or allegedly likely to result from long-term consumption of food is based on:

(1) A material violation of an adulteration or misbranding requirement prescribed by statute or regulation of the state of Missouri or the United States and the claimed injury was proximately caused by such violation; or

(2) Any other material violation of federal or state law applicable to the manufacturing, marketing, distribution, advertising, labeling, or sale of food, provided that such violation is knowing and willful, and the claimed injury was proximately caused by such violation. The provisions of subsection 3 of this section shall not preclude civil liability for breach of express contract or express warranty in connection with the purchase of food.

5. In any action exempted under subdivision (1) or (2) of subsection 4 of this section, the petition initiating such action shall state with particularity the following: the statute, regulation, or other state or federal law that was allegedly violated, the facts that are alleged to constitute a material violation of such statute or regulation, and the facts alleged to demonstrate that such violation proximately caused actual injury to the plaintiff. In any action exempted under subdivision (2) of subsection 4 of this section, the petition initiating such action shall also state with particularity facts sufficient to support a reasonable inference that the violation occurred with the intent to deceive or injure consumers or with the actual knowledge that such violation was injurious to consumers. For purposes of applying this section the pleading requirements under this section are deemed part of state substantive law and not merely procedural provisions.

6. In any action exempted under subsection 4 of this section, all discovery and other proceedings shall be stayed during the pendency of any motion to dismiss unless the court finds upon the motion of any party that particularized discovery is necessary to preserve evidence, resolve the motion to dismiss, or to prevent undue prejudice to that party. During the pendency of any stay of discovery under this subsection and unless otherwise ordered by the court, any party to the action with actual notice of the allegations contained in the petition shall treat all documents, data compilations, including electronically recorded or stored data, and tangible objects that are in the custody or control of such party that are relevant to the allegations as if they were the subject of a continuing request for production of documents from an opposing party under the Missouri rules of civil procedure. 
7. The provisions of this section shall apply to all covered claims pending on or filed after January 1, 2005, regardless of when the claim arose.

HISTORY: L. 2004 H.B. $1115 \S 537.900$

NOTES:

EFFECTIVE 1-1-05 